\title{
Analysis of Sperm Antigens by Sodium Dodecyl Sulfate Gel/Protein Blot Radioimmunobinding Method
}

\author{
Chi-Yu Gregory Lee, $*$ Yuan-Shen Huang, $†$ Ping-Chuan Hu, $\dagger$ \\ Victor Gomel,* and Alan C. Menge $\ddagger$ \\ *Department of Obstetrics and Gynaecology. The University of British Columbia, Vancouver, British \\ Columbia V6T 2B5, Canada; †Cancer Research Center, University of North Carolina, Chapel Hill. \\ North Carolina 27514; and $\ddagger$ Department of Obstetrics and Gynecology, University of Michigan \\ Medical Center, Ann Arbor, Michigan 48109
}

Received October 27, 1981

\begin{abstract}
A radioimmunobinding method based on the blotting of renatured proteins from sodium dodecyl sulfate gels on to nitrocellulose filter papers was developed to analyze the sperm antigens that elicit serum anti-sperm antibodies. In rabbits, serum anti-sperm antibodies were raised by immunization with homologous epididymal spermatozoa mixed with complete Freund's adjuvant. The raised antisera from either male or female rabbits were shown to react with three major sperm protein bands on sodium dodecyl sulfate gels with the corresponding molecular weights of about $70,000 \pm 5000,14,000$, and 13,000, respectively. In humans, the monoclonal antibodies against human sperm were raised by a hybridoma technique. Out of six independent hybrid cell lines that were generated, three of them were shown to secrete immunoglobulins that react with the same two protein bands on sodium dodecyl sulfate gels, which have the approximate molecular weight of 10,000 . The same procedure was also used to analyze human serum samples that were shown to contain anti-sperm antibodies by the known techniques. Unique sperm antigens that elicit anti-sperm antibodies in humans were identified and correlated. The results of this study suggest that sodium dodecyl sulfate gel/ protein blot radioimmunobinding method may be a sensitive and useful tool for the study of sperm antigens that elicit autoimmune responses and their association with human infertility.
\end{abstract}

It has been well established that animals immunized with homologous spermatozoa can induce auto- or isoimmune responses (1-7). In the last 30 years, numerous attcmpts have been made to identify and characterize sperm autoantigens that elicit antisperm antibodies both in experimental animals and in humans (5-7). These autoantigens may either be proteins or glycoproteins and were mainly identified on the surface of spermatozoa $(8,9)$.

In humans, the occurrence of antisperm antibodies has been implicated to associate with male or female infertility (10-12). It is commonly believed that the autoimmune and isoimmune response of certain sperm antigens in humans results in the production of anti-sperm antibodies. The presence of these antibodies in patients' sera or reproductive tracts may cause agglutination and/ or complement-dependent immobilization of spermatozoa and thus effect their fertilization capacity (13).

To analyze specific minor antigens from mixtures of total cellular proteins, immunoprecipitation technique is most commonly used (14). By this technique, solubilization and radiolabeling of cellular proteins are usually required for analysis. Moreover, coprecipitation of other membrane or particulate proteins can result in misleading interpretations. Therefore, it is desirable to employ alternative procedures for more sensitive and reliable analysis of those sperm antigens that elicit anti-sperm antibodies.

The occurrence of antisperm antibodies 
in humans is commonly analyzed by established sperm agglutination or immobilization tests (15). However, no information can be obtained from those tests regarding the exact molecular nature of autoantigens that elicit anti-sperm antibodies. Due to the lack of such information, further analysis has been difficult with respect to the chemical and biological properties of these autoantigens.

As an animal model for the study of antisperm antibodies in humans, rabbits were immunized with homologous spermatozoa to raise anti-sperm antisera. Identification of the related sperm autoantigens or isoantigens that elicit these antibodies appears to be essential for the understanding of autoimmunity and isoimmunity of spermatozoa.

Recently, we attempted to employ SDS ${ }^{1}$ $\mathrm{gel} /$ protein blot radioimmunobinding method for the molecular analysis of anti-sperm antibodies in humans and in experimental animals. By transferring the renatured proteins from SDS gels to nitrocellulose filters, a simple radioimmunobinding method can be performed and specific sperm antigens that react with antisperm antibodies can be visualized by autoradiography $(16,17)$. Preliminary results of this study are presented in this communication.

\section{MATERIALS AND METHODS}

\section{Animals}

Mature male and female rabbits (New Zealand, white randomly bred) were obtained from Charles River. Male mice of BALB/c strain (6-10 weeks old) were purchased from the Jackson Laboratory, Bar Harbor, Maine. Pooled human semen samples were obtained from healthy donors in North Carolina Memorial Hospital, University of North Carolina, Chapel Hill. Epididymal spermatozoa were obtained from mature male rabbits by surgical removal of epididymis.

\footnotetext{
' Abbreviations used: SDS, sodium dodecyl sulfate;
} PBS, phosphate-buffered saline: IgG, immunoglobulin G.

\section{Chemicals}

All the analytical grade reagents required for acrylamide gel electrophoresis were from Bio-Rad Laboratory, Richmond, California. Nitrocellulose filter papers were obtained from Millipore $(0.45-\mu \mathrm{m}$ pore size in roll form).

Iodine-125 (50 $\mathrm{mCi} / \mathrm{mmol})$ was obtained from New England Nuclear, Buston, Massachusetts. Agamma horse serum and chloramine $\mathrm{T}$ were from Sigma Chemical Company, St. Louis, Missouri. Nonidet P-40 and cellulose filter papers were from Bethesda Research Laboratory, Bethesda, Maryland. Microtiter plates were from Dynatech Laboratories, Inc., Alexandria, Virginia.

\section{Autoantibodies and Isoantibodies to Rabbit Spermatozoa}

Rabbit spermatozoa were recovered from epididymis of mature rabbits in phosphatebuffered saline (PBS). Spermatozoa were washed and collected three times by centrifugation at $500 \mathrm{~g}$ for $10 \mathrm{~min}$ in PBS. The final pellet of spermatozoa was resuspended in PBS at a final concentration of $1 \times 10^{8}$ cells $/ \mathrm{ml}$ and then homogenized with an equal volume of complete Freund's adjuvant. The mixture was injected subcutaneously to male and female rabbits on Days 1, 15, 29, and 36. The rabbits were bled on Day 43. The antisera was collected and stored at $-20^{\circ} \mathrm{C}$ until use.

\section{Monoclonal Antibodies to Human Sperm Antigens}

Antibodies to human spermatozoa were raised by two different immunization procedures. Human spermatozoa were first recovered from pooled human semen samples by centrifugation at $500 \mathrm{~g}$ for $20 \mathrm{~min}$. The spermatozoa were resuspended in PBS and sonicated for $30 \mathrm{~s}$ at $4^{\circ} \mathrm{C}$. After centrifugation at $27,000 \mathrm{~g}$ for $30 \mathrm{~min}$, the particulate fraction (sperm pellet) was resuspended in PBS. 
To raise anti-human sperm antibodies in rabbits and mice, the animals were immunized with $1 \mathrm{ml}$ particulate fraction of human sperm in PBS (originally recovered from 1 to $3 \times 10^{8}$ cells $/ \mathrm{ml}$ ) homogenized with an equal volume of complete Freund's adjuvant at biweekly intervals. The animals were bled 1 week after the third injection. To compare the differences in immune response, the rabbit anti-human sperm antibodies were also raised by immunization with the particulate fraction of human sperm that had been homogenized with $1 \%$ TritonX-100 in PBS and complete Freund's adjuvant according to the scheme as described.

To raise antibodies against specific human sperm antigens, monoclonal antibodies were raised (in BALB/c mice) by hybridoma techniques (18). Detailed protocols will be described elsewhere (19). Briefly speaking, after successive immunizations with the particulate fraction of human spermatozoa in BALB/c mice, the spleen cells were fused with P3-X63-Ag8 myeloma cells. Under conditions of selection mediums, clones of viable cells were produced. By microplate radioimmunobinding methods $(19,20)$, several clones and their subclones were shown to produce antibodies against unique human sperm antigens (19).

\section{Microplate Radioimmunobinding Method}

The presence of anti-sperm antibodies in rabbit or mouse sera was qualitatively determined by microplate radioimmunobinding method (20). Briefly, the particulate fraction of human spermatozoa was first coated in microtiter plates in the presence of carbonate buffer containing $1.59 \mathrm{~g} /$ liter $\mathrm{Na}_{2} \mathrm{CO}_{3}, 2.93 \mathrm{~g} /$ liter $\mathrm{NaHCO}_{3}, 0.2 \mathrm{~g} /$ liter of $\mathrm{NaN}_{3}$, and $0.5 \mathrm{ml} /$ liter Tween-20 (21). After overnight incubation at $4^{\circ} \mathrm{C}$, plates were washed with PBS-Tween $(8.0 \mathrm{~g} /$ liter $\mathrm{NaCl}, 0.2 \mathrm{~g} /$ liter $\mathrm{KH}_{2} \mathrm{PO}_{4}, 2.9 \mathrm{~g} /$ liter $\mathrm{Na}_{2}$ $\mathrm{HPO}_{4} \cdot 12 \mathrm{H}_{2} \mathrm{O}, 0.2 \mathrm{~g} /$ liter $\mathrm{NaN}_{3}, 0.2 \mathrm{~g} /$ liter $\mathrm{KCl}, 0.5 \mathrm{ml} /$ liter Tween-20) containing $2 \%$ agamma horse sera. Mouse or rabbit sera were added to sperm antigen-coated wells in microplates with different dilutions in PBS-Tween. After $18 \mathrm{~h}$ at $4^{\circ} \mathrm{C}$, the wells were washed three times with PBS-Tween, followed by incubation with $\mathrm{I}^{125}$-labeled goat anti-rabbit or goat anti-mouse IgG. After 2 $h$ at $37^{\circ} \mathrm{C}$, unreacted $I^{125}$-labeled anti-IgG was removed by aspirations and by three washes with PBS-Tween containing $2 \%$ agamma horse sera. The radioactivity contained in each well of microplates was determined by a Beckman gamma counter.

\section{$I^{125}$ Labeling and Autoradiography}

Goat anti-rabbit IgG, goat anti-mouse IgG, and goat anti-human IgG were labeled with $\mathrm{I}^{125}$ (sp act, $50 \mathrm{mCi} / \mathrm{mmol}$ ) according to the modified chloramine-T procedure (22). Autoradiography was performed with a Kodak X-ray film (XAR-2).

\section{Gel Electrophoresis}

Acrylamide gel electrophoresis was performed according to the conditions and procedures of Laemmli (23). For the stacking gels, $3 \%$ acrylamide and $0.1 \%$ sodium dodecyl sulfate were used. To prepare running gels, $10 \%$ acrylamide and $0.1 \%$ sodium dodecyl sulfate were adopted. SDS-acrylamide electrophoresis was conducted utilizing vertically oriented slab gels with thickness of either 0.75 or $1.5 \mathrm{~mm}$. For comparisons, samples with the particulate fraction of human sperm ( 100 to $500 \mu \mathrm{g} / \mathrm{gel})$ were prepared either with or without $\beta$-mercaptoethanol in 5\% SDS. The debris in sperm SDS samples was removed by centrifugation at $27,000 \mathrm{~g}$ for $10 \mathrm{~min}$ prior to gel electrophoresis.

\section{Protein Blot Procedure}

I. Removal of sodium dodecylsulfate from acrylamide gels. Immediately after electrophoresis, the stacking gel was removed and the running gel was placed in a renaturation buffer containing $10 \mathrm{~mm}$ Tris- 
$\mathrm{HCl}(\mathrm{pH} \mathrm{7.6)}, 50 \mathrm{~mm} \mathrm{NaCl}, 2 \mathrm{~mm}$ EDTA, $0.1 \mathrm{mM}$ dithiothreitol, $0.02 \% \mathrm{NaN}_{3}$, and 4 $M$ urea. This step ensured the removal of all SDS from the gel. The gel was incubated for 4 to $6 \mathrm{~h}$ at room temperature in two changes of $300 \mathrm{ml}$ renaturation buffer with gentle shaking.

II. Protein transfer to nitrocellulose filters. Protein transfer from slab gels to nitrocellulose filters followed the procedure as described $(16,17)$, except that natural diffusion was used instead of electrophoretic blotting. The gel to be blotted was sandwiched in the center between the two nitrocellulose sheets which had been wet in the transfer buffer (same as the renaturation buffer, except no urea). Care was taken to remove all air bubbles. A second pad of wet cellulose filter paper $(0.5 \mathrm{~cm}$ thickness $)$ was placed on either side of the nitrocellulose sheet. A stainless-steel grid and hole-punched Plexiglas were then placed outside the cellulose paper pad. The whole assembly was firmly pressed by screws and then soaked in a chamber containing transfer buffer at $37^{\circ} \mathrm{C}$ for 36 to $48 \mathrm{~h}$ incubation. After protein transfer, the nitrocellulose sheets were removed and cut into strips for immunological detection of proteins by radioimmunobinding method. The nitrocellulose strips can be stored in $-80^{\circ} \mathrm{C}$ deep freezer for at least 6 months.

III. Immunological detection of proteins on nitrocellulose sheets by radioimmunobinding method. To identify proteins on nitrocellulose strips that react with antisperm antibodies, a radioimmunobinding method was performed. Nitrocellulose strips were first soaked in an incubation buffer containing $50 \mathrm{~mm}$ Tris- $\mathrm{HCl}$ at $\mathrm{pH} 7.4,150 \mathrm{~mm}$ $\mathrm{NaCl}, 5 \mathrm{~mm}$ EDTA, $0.25 \%$ gelatin or $2 \%$ agamma horse serum and $0.05 \%$ NP-40 for $1 \mathrm{~h}$ with two changes and gentle shaking in plastic tubes. Anti-sperm antisera from either rabbit, mouse, or humans were added to the incubation buffer at a ratio of $1 / 50$ to $1 / 500$ depending on the antiserum titers. The incubation was allowed to proceed for
6-12 h with gentle shaking. After incubation, unreacted antisera was removed and the strips were washed with the incubation buffer with three changes at 30 -min intervals. Depending on the source of antisera, $I^{125}$-labeled goat anti-mouse, -rabbit, or -human IgG (radioactivity $\simeq 1 \times 10^{6} \mathrm{cpm}$ ) was added to the incubation buffer containing nitrocellulose strips that had been blotted with the known antisera. After $6 \mathrm{~h}$ to overnight incubation, the nitrocellulose strips were washed with incubation buffer three times followed by additional wash with phosphate-buffered saline to remove all the nonspecifically bound anti-IgG. Autoradiography was performed on a XAR-2 X-ray film with 2 to $24 \mathrm{~h}$ exposure before the development.

\section{RESULTS AND DISCUSSION}

\section{SDS Gel Protein Blot Procedure}

The majority of proteins that were originally stained on SDS gels were transferred to nitrocellulose sheets by natural diffusion upon close contact between the gels and nitrocellulose filters in the transfer buffer. This can be clearly demonstrated by the protein staining of nitrocellulose sheets with amido black in $45 \%$ methanol and $10 \%$ acetic acid (data not shown) after transfer.

\section{Analysis of Rabbit Sperm Antigens}

Upon immunization with homologous spermatozoa, the auto- or isoimmune response in rabbits can be clearly demonstrated by SDS gel/protein blot radioimmunobinding method. As shown in Fig. 1, the antisera from both male and female rabbits react with unique protein bands on the SDS gels of epididymal spermatozoa. Notably, protein bands with the corresponding molecular weights of 13,000 and 14,000 were commonly recognized by the antisera from both male and female rabbits. The protein band of higher molecular weight $(\simeq 70,000)$ was detected mainly with the fe- 
male antisera but weakly with the male sera. This clearly reflects the sex difference in immune response (or tiers) to the specific sperm autoantigens. In a control experiment, no apparent protein bands on nitrocellulose sheets were blotted when nonimmune rabbit sera were used for radioimmunobinding method (Fig. 1).

When the SDS-gel electrophoresis of sperm proteins was performed in the absence of $\beta$-mercaptoethanol, which is known to dissociate intra- or interprotein disulfide bonds, a significant difference in the intensity of protein bands with high molecular weights was observed for antisera from female rabbits. The lower molecular weight protein band was separated into two subbands of similar molecular size in the absence of $\beta$-mercaptoethanol.

It remains to be established if the lowmolecular-weight protein band detected by this assay procedure is related to the autoantigen isolated previously from rabbit testes $(24,25)$.

The validity of SDS gel/protein blot radioimmunobinding method remains to be confirmed by other known immunological procedures such as double-immunoprecipitation method. This involves the $\mathrm{I}^{125}$ labeling of sperm proteins, followed by double immunoprecipitation with antisperm antisera and goat anti-rabbit IgG (26). SDS-gel electrophoresis and autoradiography of the immunoprecipitated sperm proteins should reveal the same protein bands as those derived from SDS gel/protein blot radioimmunobinding method if both procedures are able to detect the proteins specifically recognized by antisera.

Unexpectedly, by SDS gel/protein blot radioimmunobinding method, we only detect a few protein bands that were autoantigens or isoantigens in rabbit spermatozoa. However, we cannot rule out the possibility that our underestimation is due to the incomplete renaturation of sperm proteins from SDS gel, so that there is little binding between the blotted proteins and antisera. On the

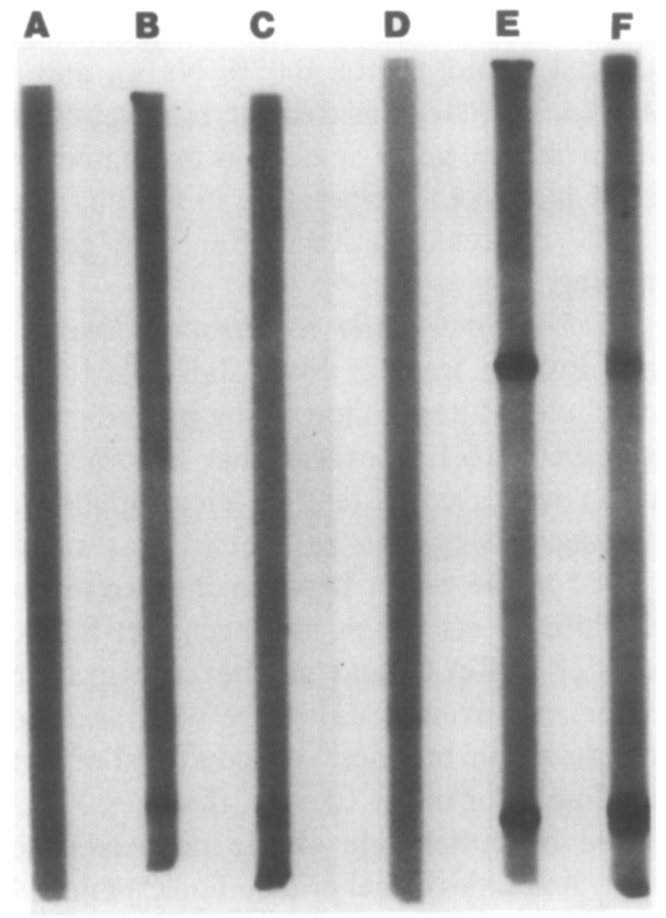

FIG. 1. Autoradiogram showing the autoantigens and isoantigens of rabbit spermatozoa that were detected by SDS gel/protein blot radioimmunobinding method. (A) Nonimmune sera (1:100 dilution) from male rabbit (SDS gel with $\beta$-mercaptoethanol, $24 \mathrm{~h}$ exposure). (B) Antisperm antisera (1:100 dilution) from male rabbit (SDS gel with $\beta$-mercaptoethanol, $6 \mathrm{~h}$ exposure). (C) Antisperm antisera (1:100 dilution) from male rabbit (SDS gel without $\beta$-mercaptoethanol, $6 \mathrm{~h}$ exposure). (D) Nonimmune sera (1:100 dilution) from female rabbit (SDS) gel with $\beta$-mercaptoethanol, $24 \mathrm{~h}$ exposure). (E) Antisperm antisera (1:100 dilution) from female rabbit (SDS gel with $\beta$-mercaptoethanol, $6 \mathrm{~h}$ exposure). (F) Antisperm antisera (1:100 dilution) from female rabbit (SDS gel without $\beta$-mercaptoethanol, $6 \mathrm{~h}$ exposure).

other hand, if the antibodies only recognize the conformational determinants of proteins in aggregated form, one would not expect the SDS gel/protein blot radioimmunobinding method to detect those protein components.

Although some of these possibilities may be ruled out by the double-immunoprecipitation procedure, the coprecipitation of proteins, especially the detergent-solubilized membrane proteins, can also be a problem 


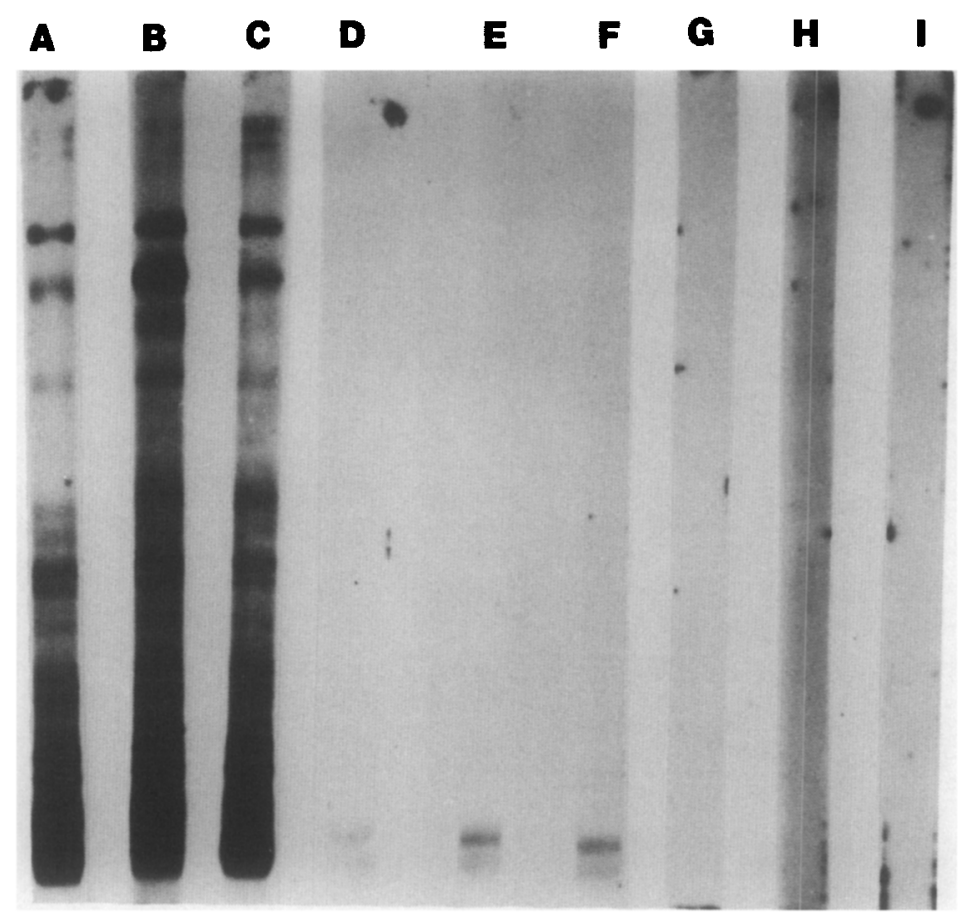

F1G. 2. Autoradiogram showing human sperm antigens that elicit antisperm antibodies by SDS gel/ protein blot radioimmunobinding method (SDS gels with $\beta$-mercaptoethanol). (A) Mouse anti-human sperm antisera (1:500 dilution, $6 \mathrm{~h}$ exposure). (B) Rabbit anti-human sperm antisera (1:500 dilution; immunization in the presence of $1 \%$ Triton X-100 and complete Freund's adjuvant; $6 \mathrm{~h}$ exposure). (C) Rabbit anti-human sperm antisera (1:500 dilution; immunization in the presence of complete Freund's adjuvant, $6 \mathrm{~h}$ exposure). (D-F) Those with monoclonal antibodies derived from hybrid cell-lines HS2039. HS206-1, and HS301-1, respectively. For HS203-9 and HS301-1, the supernatant of the cell culture fluid was used with 1:5 dilution. For HS206-1, the ascites fluid was used for assay with 1:500 dilution (all with $6 \mathrm{~h}$ exposure). (G-I) Respectively, those with monoclonal antibodies secreted from hybrid cell lines HS-202, HS204-2, and HS208-5 (all with $24 \mathrm{~h}$ exposure).

for this technique. Further comparative studies are now in progress to assess the merit of each method for identification of specific antigens.

\section{Analysis of Human Sperm Antigens}

For the biochemical and immunological characterizations of specific surface antigens of human spermatozoa, attempts were made to generate monoclonal antibodies against human spermatozoa. Unexpectedly, three out of the six independently derived hybrid cell lines in mice were shown to secrete immunoglobulins that react with the same protein bands on SDS gels of human spermatozoa. The molecular weight of these two adjacent protein bands were estimated to be about 10,000 or less. The results are shown in Fig. 2.

Obviously, these two protein bands must share the same antigenic determinant(s) so that both are recognized by the monoclonal antibodies derived from these independent hybrid cell lines. The monoclonal antibodies derived from the other three hybrid cell lines, however, did not react with any protein bands on SDS gels of human spermatozoa, even though they were shown to bind sperm antigens by microplate radioimmunobinding method. (19). One of the possible explanations to this discrepancy is that these monoclonal antibodies may only recognize the conformational determinants of human 


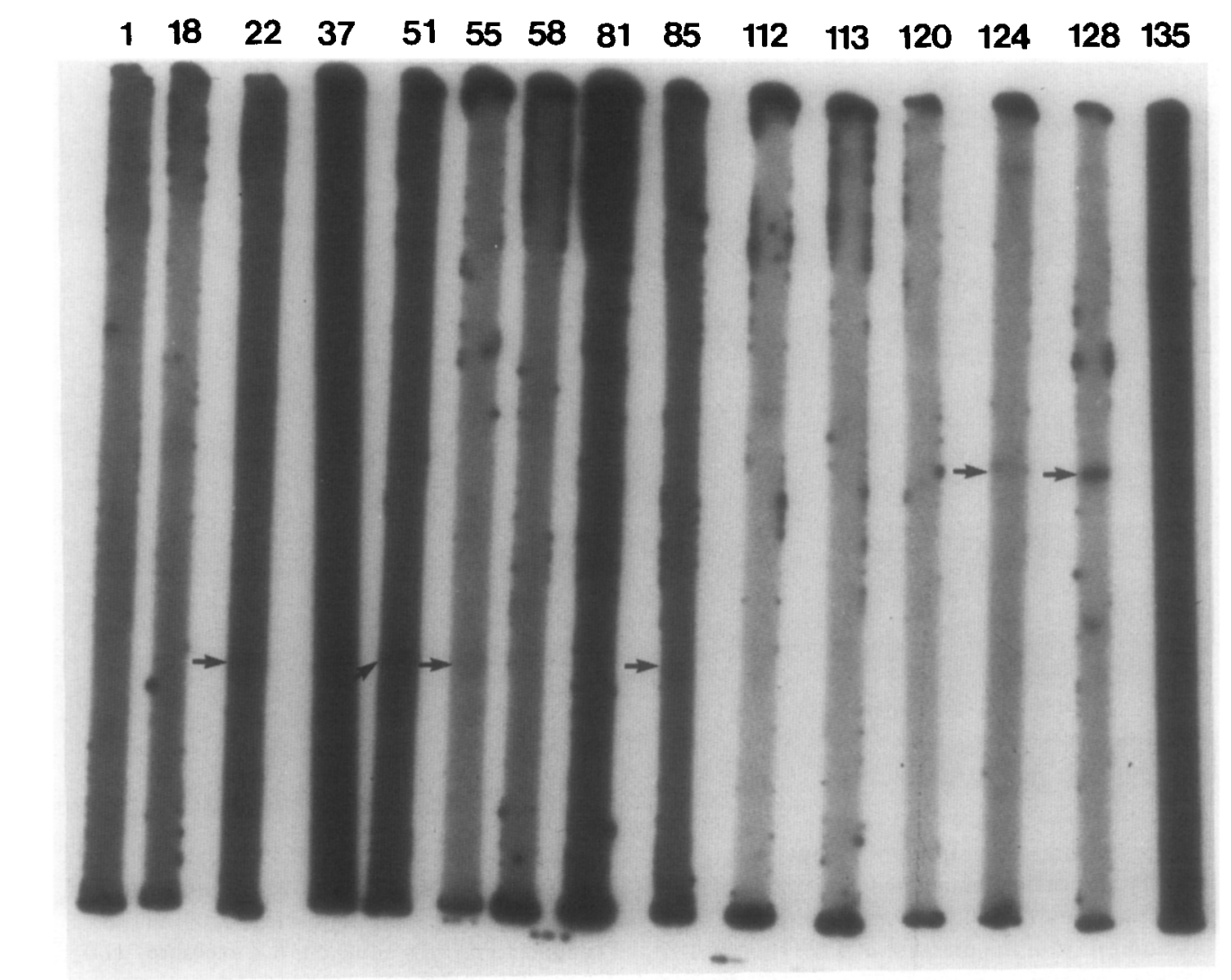

FIG. 3. Autoradiogram showing the human sperm antigens that elicit anti-sperm antibodies in human patients with unexplained infertility. Lanes from left to right (total of 15) are serum samples 1, 18, 22, $37,51,55,58,81,85,112,113,120,124,128$, and 135 , respectively, among which serum numbers 22 , $51,55,85,124$, and 128 showed unique protein band(s), as indicated by the arrows (serum diluton $1: 100,24 \mathrm{~h}$ exposure).

sperm antigens as previously discussed. Once these sperm surface antigens are separated on and renatured from SDS gels, the proper conformational determinants recognized by these monoclonal antibodies may no longer exist on those proteins that are transferred to nitrocellulose strips. It is also possible that the monoclonal antibodies secreted by these hybrid cell lines are not of IgG class, so that the protein bands cannot be recognized by $I^{125}$-labeled anti-IgG.

The fact that three out of six independent clones produce monoclonal antibodies that react with the same human sperm antigens indicates the high degree of antigenecity of these two sperm proteins. So far, little is known regarding the presence of any specific sperm antigens or antigenic determinants that are responsible for efficient induction of monoclonal antibodies. As a control, antihuman sperm antisera raised in mouse and rabbit were shown to react with almost all the protein bands that were transferred to nitrocellulose sheets from SDS gels of human spermatozoa (Fig. 2).

Recently, attempts have been made to use this new radioimmunobinding method to identify sperm antigens that elicit antisperm antibodies in human patients with unexplained infertility.

As shown in the autoradiogram presented in Fig. 3, the protein bands on nitrocellulose strips could be detected for sera of some patients. The sera of patients 51 and 22 were 
TABLE 1

Comparisons of Different Test Procedures for Anti-Sperm Antibodies in Human Patients

\begin{tabular}{|c|c|c|c|c|c|}
\hline \multirow{2}{*}{$\begin{array}{l}\text { Serum } \\
\text { sample }\end{array}$} & \multirow[b]{2}{*}{ Sex } & \multicolumn{2}{|c|}{ Titer } & \multirow{2}{*}{$\begin{array}{c}\text { Cervical } \\
\text { mucus antibody }\end{array}$} & \multirow{2}{*}{$\begin{array}{l}\text { SDS gel/ } \\
\text { protein blot }\end{array}$} \\
\hline & & Agglutination $^{a}$ & Immobilization & & \\
\hline 1 & $\mathbf{M}$ & - & - & & - \\
\hline 18 & $\mathbf{M}$ & $4096 \mathrm{t}$ & 256 & & - \\
\hline 22 & $\mathbf{M}$ & - & - & & $t^{b}$ \\
\hline 37 & $\mathrm{~F}$ & - & - & - & - \\
\hline 51 & $\mathrm{~F}$ & - & 16 & + & $t^{b}$ \\
\hline 55 & $F$ & $256 \mathrm{~h}$ & - & + & + \\
\hline 58 & $\mathrm{~F}$ & - & - & - & - \\
\hline 81 & $\mathbf{M}$ & $4096 \mathrm{t}$ & 64 & & - \\
\hline 85 & $\mathrm{~F}$ & $1024 t$ & - & + & $t^{b}$ \\
\hline 112 & $\mathrm{~F}$ & $1024 \mathrm{~h}$ & 64 & + & - \\
\hline 113 & $\mathbf{M}$ & $4096 \mathrm{t}$ & 64 & & - \\
\hline 120 & $\mathrm{~F}$ & $1024 t$ & - & - & - \\
\hline 124 & $\mathrm{~F}$ & $256 \mathrm{~h}$ & - & + & + \\
\hline 128 & $\mathrm{~F}$ & $64 \mathrm{~h}$ & 16 & + & + \\
\hline 135 & $\mathbf{M}$ & - & - & & - \\
\hline
\end{tabular}

${ }^{a}$ t, Tail-to-tail agglutination; h, head-to-head agglutination.

${ }^{b}$ Due to the high background in the autoradiogram, the detection of unique protein bands by these serum samples can only be tentative.

shown to react with a unique protein band having the molecular weight of about 30,000 (a much weaker intensity was observed with sera of patient 22). Similarly, the same protein band can also be detected with the sera of patients 55 and 85 , even though the nonspecific background of the autoradiogram is high. On the other hand, the sera from patient 128 reacts strongly with a protein band having the molecular weight of about 60,000 . The sera from patient 124 also react with same protein band on the nitrocellulose strip, although with a much weaker intensity. However, no unique protein bands could be unanimously identified when the sera of other patients were subject to the same analysis. The sera of some patients revealed no specific staining of protein bands, but with high background on the autoradiogram of nitrocellulose strips. The high background on nitrocellulose strips may arise from those sera which contain high concentrations of $\beta$-lipoprotein or lipid. The effort is being made to reduce the background of autora- diogram and to improve the sensitivity for clinical application.

The results of this analysis are summarized in Table 1 and compared with those of other known procedures for anti-sperm antibody assays, such as agglutination, immobilization, and cervical mucus antibody tests (13).

As clearly shown in this table, some disagreements among different test procedures are noticed. Perhaps, each assay procedure detects only certain specific types or aspects of anti-sperm antibodies in human patients. However, with SDS gel/protein blot radioimmunobinding method, one is able to obtain additional direct information regarding the molecular nature of sperm-antigens that elicit anti-sperm antibodies which may cause agglutination and immobilization of human spermatozoa in vitro and in vivo (26). With the help of this new immunobinding method, it is possible to identify and to isolate in the future these specific sperm antigens for further test of this hypothesis. The 
methodology described in this paper might provide a sensitive and useful tool for the clinical investigations regarding the sperm antigens to anti-sperm antibodies and their association with human infertility.

\section{ACKNOWLEDGMENTS}

This research work was supported in part by research grants from British Columbia Health Care and Research Foundation (5-81-1) and from Canadian Medical Research Council (MA-7707).

\section{REFERENCES}

1. Voisin, G. A., Delaunay, A., and Barar, M. (1951) Ann. Inst. Pasteur Paris 81, 48.

2. Freund, J., Lipton, M. M., and Thompson, G. E. (1953) J. Exp. Med. 97, 711.

3. Freund, J., Lipton, M. M., and Thompson, G. E. (1955) J. Exp. Med. 101, 591.

4. Voisin, G. A., and Toullet, F. (1971) Folia Allergol. 18, 310.

5. Bishop, D. W., and Carlson, G. L. (1965) Ann N. Y. Acad. Sci. 124, 247.

6. Brown, P. C., Holborow, E. J., and Glynn, L. E. (1965) Immunology 9, 255.

7. Voisin, G. A., Toullet, F., and D'Almeida, M. (1974) Karolinska Symp. Res. Methods Reprod. Endorcrinol. 7th. 173-201.

8. Jackson, J. J., Hagopian, A., Carlo, D. J., Linjuco, G. A., and Eylar, E. H. (1975) J. Biol. Chem. 250, 6141.

9. Jackson, J. J., Hagopian, A., Carlo, D. J., Linjuco, G. A., and Eylar, E. H. (1976) Biochim. Biophys. Acta 427, 251.

10. Rumke, P., and Hellinga, G. (1959) Amer. J. Clin. Pathol. 32, 357.
11. Shulman, S. (1971) Clin. Exp. Immunol. 9, 267.

12. Rumke, P., VanAmstel, N., Messer, E. N., and Bezemer, P. D. (1974) Fertil. Steril. 25, 393.

13. Menge, A. C. (1980) Immunological Aspects of Infertility and Fertility Regulation, pp. 205-224, Elsevier/North-Holland, Amsterdam.

14. Ansari, A. A., Bahuguna, L. M., and Malling, H. V. (1979) I. Immunol. Methods 26, 203.

15. Boettcher, B., Hjort, T., Rumke, P. H., Shulman, S., and Vyazov, O. E. (1977) Acta Pathol. Microbiol. Scand. Sect. C Suppl. 258.

16. Towbin, H., Stachelin, T., and Gordon, J. (1979) Proc. Nat. Acad. Sci. USA 76, 4350-4354.

17. Hu, P. C., Huang, Y.-S., Graham, J. A., and Gardner, D. E. (1981) Biochem. Biophys. Res. Commun. 103, 1363-1370.

18. Kohler, G., and Milstein, C. (1975) Nature (London) 256, 495-497.

19. Lee, C.-Y., Hu, P.-C., Huang, C.-H., Huang, Y.-S., and Menge, A. S. (1982) J. Reprod. Immunol., in press.

20. Engvall, E., and Perlmann, P. (1972) J. Immunol. 109, 129.

21. Voller, A., Bidwell, D. E., and Bartlett, A. (1979) The Enzyme Linked Immunosorbent Assay (ELISA), pp. 35-42, Dynatech Lab., Inc., Alexandria, Va.

22. Greenwood, F. C., and Hunter, W. M. (1963) Biochem. J. 99, 114.

23. Laemmli, U. K. (1970) Nature (London) 227, 680.

24. O'Rand, M. G., and Porter, J. P. (1979) J. Immunol. 122, 1248-1254.

25. O'Rand, M. G. (1980) Immunological Aspects of Infertility and Fertility Regulation, pp. 155-171, Elsevier/North-Holland, Amsterdam.

26. Hugh, E. N., and August, J. T. (1981) J. Biol. Chem. 255, 644-671. 